\title{
MatK ve trnH-psbA Barkot Genleri Kullanılarak Bazı Bitki Taksonlarının Moleküler Olarak Sınıflandırılması*
}

\author{
Behcet INAL ${ }^{1}$, Mehmet KARACA ${ }^{2 * *}$ \\ ${ }^{\prime}$ Siirt Üniversitesi, Ziraat Fakültesi, Tarımsal Biyoteknoloji Bölümü, Siirt, TÜRKIYE \\ ${ }^{2}$ Akdeniz Üniversitesi, Ziraat Fakültesi, Tarla Bitkileri Bölümü, Antalya, TÜRKIYYE
}

\begin{tabular}{ll}
\hline \multicolumn{1}{c}{ Geliş Tarihi/Received: 27.11 .2018} & Kabul Tarihi/Accepted: 14.01 .2019 \\
\hline ORCID ID (Yazar sırasina göre / by author order) & \\
\hline (D) orcid.org/0000-0003-2215-2710 (D)orcid.org/0000-0003-3219-9109 \\
${ }^{* *}$ Sorumlu Yazar/Corresponding Author: mkaraca@akdeniz.edu.tr
\end{tabular}

Öz: Canlıların sınıflandırılması ve canlı birliklerine ait sınırların çizilmesi gözleme ve deneye dayalı sistemli bilgi üretmeye başlanmasıyla birlikte karşılaşılan en karmaşık problemlerden biri olmuştur. Bu amaçla araştırmacılar birçok kuram ve metot geliştirerek var olan canlı çeşitliliğini saptamaya çalışmışlardır. Çekirdek kökenli barkot bölgeleri, plastid kökenli barkot bölgelerine göre çok daha fazla bilgi içermesine karșın, tek lokus kullanılarak barkotlama yapıldığında, farklı bitki gruplarını karşılaştırabilmek için yeterli bilgiye sahip olunmamaktadır. Tüm bitki türlerinde kullanılabilecek tek bir barkot bölgesi henüz mevcut değildir ve bu nedenle farklı barkot bölgelerinin birlikte kullanılması, türlerin ayırt edilebilme gücünü arttırabilmektedir. Çalışmanın ana hedefi, bitki moleküler filogenetiğini konu alan çalışmalarda etkin olarak kullanılabilecek gen, gen bölgesi ve gen sayısını değerlendirmektir. Bu çalışmada, 15 farklı bitki ailesine ait toplam 60 bitki türüne ait filogenetik ilişkiyi değerlendirmek için matK, ve trnH-psbA barkot genler kullanılarak MAFFT (Multiple Alignment Using Fast Fourier Transform) yazılımı ile diziler hizalanmış ve Bayesian metodu ile konsensus filogenetik ağaç elde edilmiştir. Sonuçlar bitki moleküler filogenetik çalışmalarında matK gen dizilerinin $t r n \mathrm{H}-p s b \mathrm{~A}$ gen dizilerine göre daha yüksek ardıl olasılık değerli ağaç üretebildiğini göstermiştir. Ancak daha fazla genlerin çalışması ile olası filogenetik ilişki daha da iyi bir şekilde tahmin edilebilir.

Anahtar Kelimeler: Filogeni, moleküler sistematik, biyoinformatik, barkot gen

\section{Molecular Classification of Some Plant Taxa Using MatK and trnH-psbA Barcode Genes}

\begin{abstract}
The classification of living creatures and the demarcation of living units have been one of the most complex problems encountered as a result of observing experimental and systematic information. For this purpose, researchers have tried to determine the diversity of living creatures by developing many theories and methods. Although the nuclear genome barcode regions contain much more information than the barcode regions of plastid, they do not have enough information to compare different plant groups when barcoding with a single locus. A single barcode region that can be used in all plant species is not yet available, and therefore, the use of different barcode regions may increase the distinguishing power of species. Main objective of this study was to determine gene, gene region and numbers of genes suitable for plant molecular phylogentic studies. In this study, matK, and $t r n \mathrm{H}-p s b \mathrm{~A}$ barcode genes were used to evaluate the phylogenetic relationship of 60 plant species belonging to 15 different plant families. Sequences were aligned with MAFFT (Multiple Alignment Using Fast Fourier Transform) software and a consensus phylogenetic tree was constructed by the Bayesian method. Results indicated that mat $\mathrm{K}$ gene was much more suitaable in comparison to $t r n \mathrm{H}-p s b \mathrm{~A}$ region since the use of mat $\mathrm{K}$ produced trees with higher posterior probability values. However, further studies clearly showed that increased number of genes produced much better phylogenetic estimations.
\end{abstract}

Keywords: Phylogeny, molecular systematics, bioinformatics, barcode gene

": Bu çalışma; Akdeniz Üniversitesi, Fen Bilimleri Enstitüsü tarafından kabul edilen birinci yazara ait "Bitki Moleküler Filogenisinde Kullanılan Bazı Gen ve Metodların Karşılaştırılması” isimli Yüksek Lisans Tez çalışmasının bir bölümünden üretilmiştir. 


\section{Giriş}

Bitki moleküler sistematiği, özellikle son 20 yıldır hızla gelişmektedir (Wen ve ark., 1997). Bu gelişme DNA ve aminoasit dizi analizlerinin kullanılmasıyla ve yeni filogenetik analiz metotlarının bulunmasıyla (Ro ve ark., 2007) moleküler sistematiğe de katkı sağlamaya başlamıştır. Filogenetik bilgi açısından morfolojik karakterlerin yetersiz olduğu durumlarda dizi analizleri filogenetik analizler için çok faydalı olmaktadır (Yokoyama ve ark., 2000). Çünkü filogenetikçiler, genellikle dizilerin kendi filogenisinin organizmaların filogenisine çok yakın olduğunu düşünmektedirler. Dizi analiz yöntemleri canlıların coğrafik orijinlerinin bulunmasından canlıların filogenilerini moleküler olarak ispatlamaya kadar birçok alanda kullanılmaktadır (Allan ve ark., 2004; Cohen ve Weydmann, 2005). Angiospermlerin moleküler filogenileri hakkında yapılan çalışmalarda genellikle kloroplast (plastid) (Graham ve Olmstead 2000), mitokondri genleri (Qui ve ark., 1999) veya çok tekrarlı nüklear ribozomal DNA (nrDNA) genleri kullanılmıştır.

Günümüze kadar bilinen yaklaşık 300000 bitki türü olduğu tahmin edilmektedir. Ancak klasik sistematik metodları kullanılarak bu bitkilerin oldukça az bir kısmı doğru bir şekilde teşhis edilebilmektedir (Hollingsworth ve ark., 2011; Li ve ark., 2015). Hâlihazırda 250 yıldan beri çeşitli çalışmalarda kullanılan klasik sistematik; "bireyler morfolojik olarak birbirlerine ne kadar çok benzerlik taşıyorsa o kadar yakın akrabadır" yaklaşımı kabul edilmektedir. $\mathrm{Bu}$ bağlamda "morfolojik tür" tanımı oldukça sübjektiftir. Taksonomik yaklaşımlar uygulanırken doğada hiçbir zaman türün meydana gelmediği, ancak bireyler ve popülasyonları meydana getirdiği dikkate alınmamaktadır. Bitki popülasyonlarında gen akışının oldukça sık meydana gelmesi, bireyler arasında ekolojik farklılıkların, melezlenmenin, epigenetiğin ve genetik sürüklenmenin etkilediği değişimlerin, türlerin morfolojik olarak sabit olamamasına tam tersi dinamik bir yapıya neden olduğu bilinmektedir. DNA barkotlama, genom üzerinde daha önceden belirlenmiş ya da teşhis edilmiş bölgelerde bulunan genelde kısa (600-1500 bç) DNA dizilerinden yola çıkarak takson/türlerin teşhis edilmesini sağlayan güvenilir bir teşhis tekniğidir (Lahaye ve ark., 2008). Bu yaklaşım, ayrıca teşhis etmesi nispeten zor canlı grupları arasındaki var olan filogenetik ilişkiyi de ortaya koyabilmektedir. Bitkiler aleminde, kloroplast organel genomundaki bölgelere örnek olarak, organel genler olan; $a t p \mathrm{~F}-a t p \mathrm{H}, t r n \mathrm{~L}, r b c \mathrm{~L}, y c f 5$, rpoC1, rpoB, psbA-trn $\mathrm{H}, \quad p s b \mathrm{~K}-p s b \mathrm{I}$ ile nüklear (çekirdek) genomda bulunan Transkripsiyonu
Yapılan İç Ara Bölgeler (Internal Transcribed Spacer, ITS) gen bölgeleri bitki DNA barkot genleri arasından yaygın olarak kullanılanlarıdır (Kress ve Erickson, 2007; Ford ve ark., 2009; Phong ve ark., 2018). Daha önceki çalışmalara göre, $r b c \mathrm{~L}+$ mat $\mathrm{K}$ bileşiminden oluşan plastid barkot gen bölgeleri güvenilir ve uygulanabilir bitki barkot adayları olarak öne sürülmüştür (Hollingsworth ve ark., 2011). MatK gen bölgesi, yüksek substitüsyon oranına sahip olması, tüm üçlü kodonlarda hemen hemen eşit hızda substitüsyonların meydana gelmesini sağlar (Hilu ve Liang 1997; Hochbach ve ark., 2018). Ayrica söz konusu bu genin sahip olduğu fazla substitüsyon hızı parsimonik anlamda bilgi içeriğine sahip bölgelerin oluşmasında ve güçlü filogenetik öngörülerin elde edilmesinde ve değişik takson düzeylerinde evrimsel geçmişin nasıl geliştiğini değerlendirmede önemli bir şekilde yol göstermektedir (Johnson ve Soltis, 1994). MatK 841 nükleotid uzunluğuna sahip olup moleküler bitki sistematiği çalışmalarında en çok uygulama yeri bulunan ve çalışmalar noktasında çeşitlilik gösteren kloroplast genomunda kodlama yapan bir bölge olarak bilinmektedir (Hilu ve Liang, 1997; Hochbach ve ark., 2018). Kodlama yapmayan genler arası organel genom bölgesi olan trnH-psbA plastid barkot belirteci, bitki moleküler sistematik çalışmalarında oldukça yaygın kullanılmaktadır. Daha önce yapılan çalışmalarda, trnH-psbA barkot geninin Alnus, Quercus ve Salix gibi taksonlarda $r b c \mathrm{~L}+$ matK barkot gen bileşiminden daha etkili olduğu bulunmuştur (Piredda ve ark., 2010; Ren ve ark., 2010; Von Crautlein ve ark., 2011).

$\mathrm{Bu}$ çalışmada amaç, kloroplast organel genomuna ait barkot genler kullanılarak, 15 farklı bitki ailesine ait toplam 60 bitki türünde olası filogenetik ilişki ortaya çıkarmaktır.

\section{Materyal ve Yöntem}

Çalışmada materyal olarak, tek çenekli ve çift çenekli bitkilerden oluşan otsu, ağaçsı ve çalı formunda toplam 15 farklı aileden oluşan 60 bitki taksonu ve bunlara ait organel genom dizileri kullanılmıştır.

\subsection{Gen ve ara bölge dizilerin elde edilmesi}

Taksonlar arsındaki filogenetik ilişkiyi belirlemek üzere, $m a t \mathrm{~K}$ ve $t r n \mathrm{H}-p s b \mathrm{~A}$ genlerine ait diziler, NCBI (National Center for Biotechnology Information) veri tabanındaki "Batch Entrez" bağlantısı ile FASTA (Fast Adaptive Shrinkage Thresholding Algorithm) formatında indirilmiş ve hard disk ortamına kayıt edilmiştir. Tablo 1'de bu dizilere ait Gene Bank Dizi Kimlik Numaraları (GI) gösterilmektedir. Çalışmaya dâhil edilen her bir takson iki tekrarlı olarak çalışılmıştır. 
Tablo 1. Çalışmada kullanılan 60 taksona ait genlerin ve GI numaraları

\begin{tabular}{|c|c|c|c|}
\hline Familya & Tür ad1 & $m a t K$ & $\operatorname{trnH}-p s b A$ \\
\hline Anacardiaceae & Rhus gueinzii Sond. & 167890190 & 167890911 \\
\hline Anacardiaceae & Rhus gueinzii Sond. & 167890192 & 167890912 \\
\hline Anacardiaceae & Rhus leptodictya Diels & 167890196 & 167890914 \\
\hline Anacardiaceae & Rhus leptodictya Diels & 167890198 & 167890915 \\
\hline Anacardiaceae & Rhus transvaalensis Engl. & 167890202 & 167890917 \\
\hline Anacardiaceae & Rhus transvaalensis Engl. & 167890204 & 167890919 \\
\hline Apiaceae & Heteromorpha arborescens Cham. \& Schltdl. & 167890164 & 167890905 \\
\hline Apiaceae & Heteromorpha arborescens Cham. \& Schltdl. & 167890166 & 167890906 \\
\hline Apiaceae & Steganotaenia araliacea Hochst. & 167890212 & 167890923 \\
\hline Apiaceae & Steganotaenia araliacea Hochst. & 167890214 & 167890924 \\
\hline Arecaceae & Hyphaene coriacea Gaertn. & 167890172 & 167890844 \\
\hline Arecaceae & Hyphaene coriacea Gaertn. & 167890174 & 167890845 \\
\hline Arecaceae & Hyphaene petersiana Klotzsch ex Mart & 167890180 & 167890848 \\
\hline Arecaceae & Hyphaene petersiana Klotzsch ex Mart & 167890182 & 167890849 \\
\hline Asteraceae & Brachylaena huillensis O.Hoffm. & 167890074 & 167890860 \\
\hline Asteraceae & Brachylaena huillensis O.Hoffm. & 167890076 & 167890861 \\
\hline Combretaceae & Combretum collinum Fresen. & 167890086 & 167890866 \\
\hline Combretaceae & Combretum collinum Fresen. & 167890088 & 167890867 \\
\hline Combretaceae & Combretum apiculatum Sond. & 167890080 & 167890863 \\
\hline Combretaceae & Combretum apiculatum Sond. & 167890082 & 167890864 \\
\hline Euphorbiaceae & Croton megalobotrys Müll.Arg. & 167890102 & 167890875 \\
\hline Euphorbiaceae & Croton megalobotrys Müll.Arg. & 167890104 & 167890876 \\
\hline Euphorbiaceae & Croton gratissimus Burch & 167890096 & 167890872 \\
\hline Euphorbiaceae & Croton gratissimus Burch & 167890098 & 167890873 \\
\hline Fabaceae & Acacia tortilis Hayne & 167890060 & 167890855 \\
\hline Fabaceae & Acacia tortilis Hayne & 167890062 & 167890856 \\
\hline Loganiaceae & Strychnos decussata (Pappe) Gilg & 167890220 & 167890926 \\
\hline Loganiaceae & Strychnos decussata (Pappe) Gilg & 167890221 & 167890927 \\
\hline Loganiaceae & Strychnos madagascariensis Spreng. ex Baker & 167890223 & 167890929 \\
\hline Loganiaceae & Strychnos madagascariensis Spreng. ex Baker & 167890225 & 167890930 \\
\hline Malvaceae & Grewia flavescens Juss. & 167890152 & 167890900 \\
\hline Malvaceae & Grewia flavescens Juss. & 167890154 & 167890901 \\
\hline Malvaceae & Grewia bicolor Juss. & 167890146 & 167890897 \\
\hline Malvaceae & Grewia bicolor Juss. & 167890148 & 167890898 \\
\hline Moraceae & Ficus abutilifolia Miq & 167890128 & 167890888 \\
\hline Moraceae & Ficus abutilifolia Miq & 167890130 & 167890889 \\
\hline Moraceae & Ficus glumosa Delile & 167890134 & 167890891 \\
\hline Moraceae & Ficus glumosa Delile & 167890136 & 167890892 \\
\hline Myrothamnaceae & Myrothamnus flabellifolia Welw. & 167890184 & 167890908 \\
\hline Myrothamnaceae & Myrothamnus flabellifolia Welw. & 167890186 & 167890909 \\
\hline Orchidaceae & Clowesia warczewiczii (Lindl. \& Paxton) Dodson & 167889940 & 167890789 \\
\hline Orchidaceae & Clowesia warczewiczii (Lindl. \& Paxton) Dodson & 167889942 & 167890790 \\
\hline Orchidaceae & Encyclia alata (Bateman) Schltr. & 167889960 & 167890799 \\
\hline Orchidaceae & Encyclia alata (Bateman) Schltr. & 167889962 & 167890800 \\
\hline Orchidaceae & Ponthieva racemosa (Walter) C.Mohr & 167890008 & 167890823 \\
\hline Orchidaceae & Ponthieva racemosa (Walter) C.Mohr & 1678900010 & 167890824 \\
\hline Orchidaceae & Prosthechea fragrans (Sw.) W.E.Higgins & 167890016 & 167890828 \\
\hline Orchidaceae & Prosthechea fragrans (Sw.) W.E.Higgins & 167890018 & 167890829 \\
\hline Orchidaceae & Stanhopea saccata Bateman & 167890032 & 167890836 \\
\hline Orchidaceae & Stanhopea saccata Bateman & 167890034 & 167890837 \\
\hline Orchidaceae & Trichopilia tortilis Lindl. & 167890036 & 167890838 \\
\hline Orchidaceae & Trichopilia tortilis Lindl. & 167890038 & 167890839 \\
\hline Proteaceae & Faurea rochetiana Chiov. ex Pic.Serm. & 167890116 & 167890882 \\
\hline Proteaceae & Faurea rochetiana Chiov. ex Pic.Serm. & 167890118 & 167890883 \\
\hline Proteaceae & Faurea saligna Harv. & 167890122 & 167890885 \\
\hline Proteaceae & Faurea saligna Harv. & 167890124 & 167890886 \\
\hline Solanaceae & Solanum panduriforme Drège ex Dunal & 167890206 & 167890920 \\
\hline Solanaceae & Solanum panduriforme Drège ex Dunal & 167890208 & 167890921 \\
\hline Velloziaceae & Xerophyta retinervis Baker & 167890236 & 167890936 \\
\hline Velloziaceae & Xerophyta retinervis Baker & 167890238 & 167890937 \\
\hline
\end{tabular}




\subsection{Dizilerin analizi}

Çoklu alignment (hizalama) çalışmaları için çoklu hizalama programlarından en yaygın olan "Multiple Alignment with Fast Fourier Transform" (MAFTT) yazılım programı kullanılmıştır. Hizalama çalışmaları için iki farklı algoritmadan yararlanılmıştır. Birinci algoritmada MAFTT programinın varsayılan "default" ve ikinci algoritma olarak ise tekrar sayıları, boşluk uzunlukları ve boşluk uzunluk kısıtlamaları değerlendirilmiștir. Analiz sonuçları Nexus formatına dönüştürülmüştür (İnal ve ark., 2017).

\subsection{Filogenetik analiz çalışmaları}

Çalışmada, MrBayes v.3.1.2 (Ronquist ve Huelsenbeck, 2003) yazılım programı kullanılmış olup; filogenetik ağaçların tahmini için ardıl olasılık (posterior) istatistiksel yaklaşım kullanan, Bayesian yönteminden faydalanılmıştır. Filogenetik çalışmalarda, GTR (Generalised Time Reversible) SBT (Sabtitüsyon) modeli kullanılmıştır. Filogenetik ağaç tahmininde Markov Zinciri Monte Carlo (MCMC) yöntemi kullanılmıştır. Verilerden en iyi topolojileri elde etmek için, bölünmüş frekansın ortalama standart sapması 0.05 değerinin altına indiği ana kadar simüle edilmiştir. Ortalama standart sapmanın düşük olması, analizin güvenilir olduğunu da göstermektedir.

\subsection{Filogenetik ağaçların elde edilmesi}

Çalışmada konsensus ağaçlar FigTree 1.3.1 programı ile görselleştirilmiştir ve daha sonra PhotoShop programiyla renklendirme ve harflendirme çalışmaları gerçekleştirilmiştir. Elde edilen ağaçların nodlarında ardıl olasılık (posterior probality) değerleri \% 50 ve daha fazla olanlar önemli, küçük olan değerler ise önemsiz ilişki olarak değerlendirilmiştir.

\section{Bulgular ve Tartışma}

$\mathrm{Bu}$ çalışmada bitki moleküler filogenetiğini konu alan çalışmalarda etkin olarak kullanılabilecek gen, gen bölgesi, gen sayısı için filogenetik analiz yöntemleri ile değerlendirilmiştir. Elde edilen filogenetik ağaçların ardıl olasılık (posterior probality) değerleri yüksek olarak olan gen, gen bölgesi veya gen sayısı tespit edilmiştir. Sonuçlar değerlendirildiğinde çalışmada ele alınan verileri en doğru şekilde ilişkilendiren MAFFT programı olduğundan bu çalışmada sadece MAFFT ile elde edilen sonuçlar verilmiştir (İnal ve ark., 2017; Yang ve ark., 2018).

Çalışmada her bir gen için ayrı filogenetik ağaçlar elde edilmiş ve bunlar Şekil 1a ve 1b'de gösterilmiştir. Gen sayılarının etkilerini belirlemek için ise her iki gen birlikte değerlendirilmiştir. matK geninin analiz sonucu ortaya koyduğu ağaç topolojisinde; Acacia, Ficus, Combertum, Croton, Grewia, Rhus cinslerinin kendi içinde \% 100 ardil olasılık değeriyle desteklendiği görülmüştür. Brachylaena, Heteromorpha, Steganotaenia, Solanum ve Strychnos cinslerinin kendi içinde $\% \quad 100$ ardıl olasılık değeriyle desteklendiği görülmüştür. Bu iki grup ayrı değerlendirildiğinde ise birbirlerinden \% 76 ardıl olasılık değeriyle desteklenmiştir (Şekil 1a).

$\mathrm{Bu}$ iki gruba daha sonra Myrothamnus ve Faurea cinslerinin yüksek ardıl olasılık (\% 100 ve \% 99) değerleri ile bağlanmış olduğu tespit edilirken, Hyphaene ve diğer cinsler sadece \% 52 ardıl olasılık değeriyle bağlanabilmişlerdir (Şekil 1a). Çalışmada kullanılan diğer cinslerden Stanhopea ve Trichopila \% 99, Encyclia ve Prosthechea \% 100, bu cinslerin oluşturduğu grup ise Ponyhieva cinsine \% 99 ardıl olasılık değeriyle bağlanmışlardır (Şekil 1a).

Sonuçlar değerlendirildiğinde matK genine ait ağaç topolojisinde, çalışmada kullanılmış olan 15 ailenin ve cinsin tümü kendi aralarında uyumlu bir şekilde kümelenmiştir. Oluşan kümeler yüksek ardıl olasılık değeriyle desteklenmiştir. Ayrıca monokotil (tek çenekli) bitki grubunu oluşturan Orchidaceae, Arecaceae, Velloziaceae ailelerini $\% 100$ bir ardıl olasılık desteği ile bir arada göstermiştir. Ancak, Proteaceae ailesine ait $F$. rochetina türünü ve Arecaceae ailesine ait $H$. coriacea türlerini polifiletik göstermiş olup kardeş türleri ile tek kümede olacak şekilde göstermemiştir.

Şekil 1b'de trnH-psbA genleri arasındaki bölgenin analizi sonucu elde edilen ağaç topolojisi verilmiştir. Konsensus ağacında cinsler üç ana gruba ayrılmış olup, Ficus cinsini temsil eden iki türün altı bireyi de çalışmada kullanılan bütün cinslerden ayrılmıştır. trnH-psbA genleri arasındaki bölgenin kullanılmasıyla bu cins içerisindeki iki türü temsil eden örnekler arasındaki filogenetik ilişki doğru olarak ortaya konulamamıştır. Rhus cinsinin altı bireyi, Faurea cinsinin dört bireyi, Hyphaene cinsinin dört bireyi, Combretum cinsinin dört bireyi, Strychnos cinsinin dört bireyi, Croton ve Grewia cinsinin dörder bireyi kendi aralarında gruplandırılmıştır. Gruplamalardaki ardıl olasılık değeri oldukça yüksek ve ilişkiler de beklenen düzeyde elde edilmiştir. İlişkilerin bir kısmının ardıl olasılık değerleri ellinin altında çıkmıştır (Şekil 1b).

$\operatorname{trn} \mathrm{H}-p s b \mathrm{~A}$ topolojisinde aileler uyumlu olacak şekilde bir arada kümeleşmişlerdir. Ayrıca monokotil bitki grubunu oluşturan Arecaceae, Velloziaceae, Orchidaceae aileleri \%95 ardil 


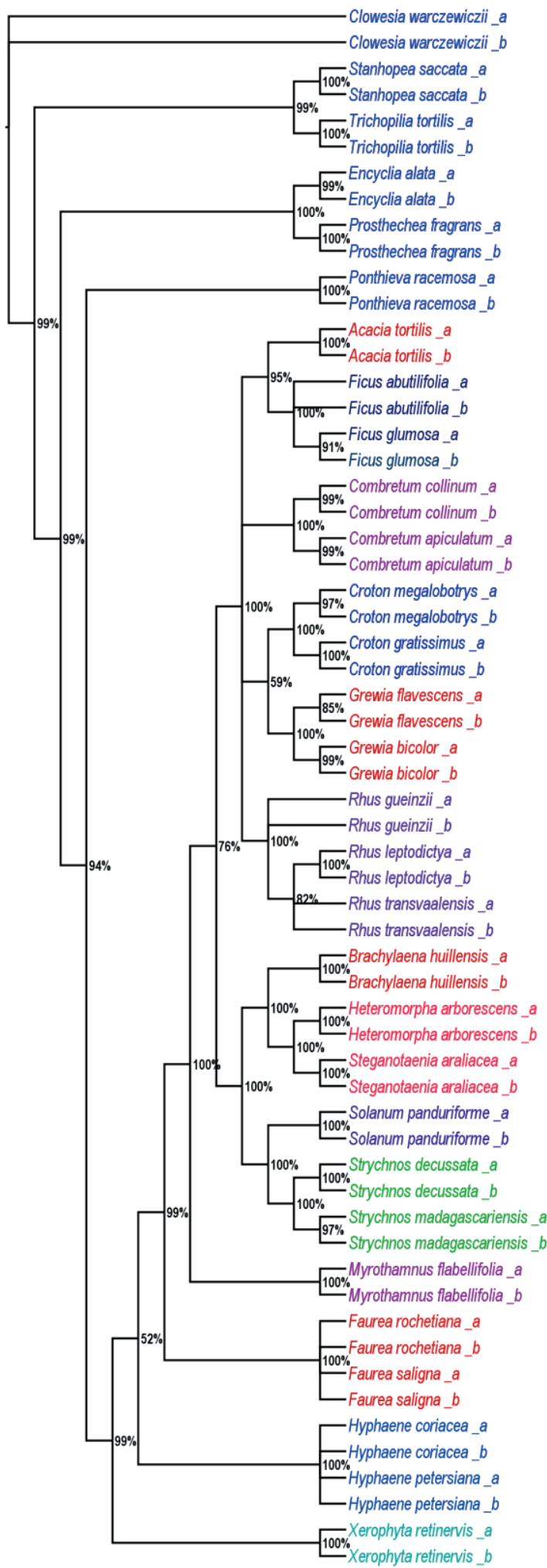

a

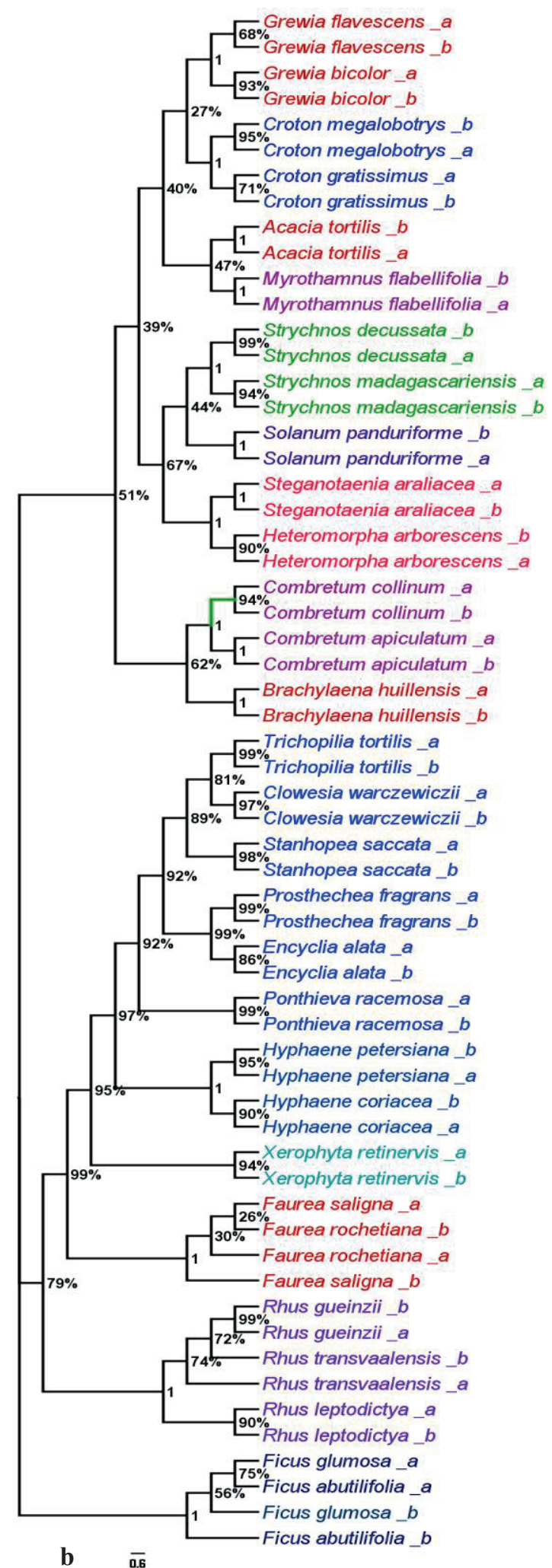

flavescens _o

Grewia bicolor

Croton megalobotrys _b

- Acacia tortilis b

Acacia tortilis

Myrothamnus flabellifolia

Strychnos madagascariensis _a

Solanum panduriforme_b

$90 \%$ Heteromorpha arborescens_b

-Combretum collinum_a

Brachylaena huillensis _b

Trichopilia tortilis a

Ponthieva racemosa

95\%

Hyphaene coriacea

Rhus transvaalensis

Ficus abutilifolia b

Şekil 1. a) matK geni konsensus filogenetik ağacı. MAFFT programının 1. parametresi ile hizalanmış matK gen dizisinin GTR SBT modelindeki Bayes analizi*; b). trnH-psbA intergenik bölgenin konsensus filogenetik ağacı. MAFFT programının 1. parametresi ile hizalanmış trnH-psbA gen sekansının GTR SBT modelindeki Bayesian analizi**

*: Nodlarda bulunan yüzde değerler ardıl olasılık değerleridir; ${ }^{* *}:$ Nodlarda bulunan yüzde değerler ardıl olasılık değerleridir. Nodlarda 1 ile gösterilen rakamlar \% 100 ardıl olasılık değerleridir. 
olasılık değeri desteği ile bir arada göstermiştir. Cins ve tür bazında büyük oranda bir monofiletiklik görülmüştür (Şekil 1b).

Çalışmanın hedeflerinden olan gen sayısının filogenetik çalışmalarda önemliliğini ortaya koymak için her iki gen bölgesinin birlikte kullanılarak gerçekleştirilen analizlerde; her iki genin birlikte kullanılmasıyla ard1l olasılık değerinde artışın olduğu, diğer taraftan da bazı cinsler arasındaki ilişkinin daha net olarak ortaya konulduğu görülebilmiştir. Çalışmada elde edilen türlere ait akrabalık ilişkilerinin tam olarak ortaya konulabilmesi için daha fazla çalışmanın gerekliliği açık olmakla birlikte, gen sayısının filogenetik çalışmalarda önemli olduğu, fazla gen dizileri kullanarak yapılan tahminlerin daha gerçekçi olabileceği sonucuna varılmıştır.

Sonuçlar birlikte değerlendirildiğinde, bu çalışma kapsamında matK ve trnH-psbA genlerinin markır gen olma başarılarının birbirine çok yakın olduğu görülmüştür. İkisi de biri ortak, iki familya bir polifiletiklik göstermiştir. Ancak matK geni monokotil gruplarını \% 100 ardıl olasılık desteği ile bir arada göstermişken trnH-psbA geni ise bu grupları \% 95 ardıl olasılık desteği ile bir arada göstermiştir. Önceki çalışmalarda trnH-psbA geninin karasal bitkiler için uygun bir markır geni olduğunu belirtmişlerdir. Aynı zamanda daha önce yapılmış bir çalışmada trn $\mathrm{H}-p s b \mathrm{~A}$ ve matK gen bölgelerinin türleri birbirinden ayırmada başarılı olduğunu belirtmişlerdir (Krees ve ark., 2007; Lahaye ve ark., 2007; Lei ve ark., 2018; Yang ve ark., 2018).

\section{Sonuçlar}

Filogenetik Sistematik taksonomiyi filogenetik yönüyle inceleyen alandır. Bir takson ya da takson grubunun filogenilerinin belirlenmesi demek, zamansal olarak (önce-sonra) onların birbiri ile ve diğer taksonlarla ortak ata temelinde durumlarının ortaya konması demektir. Günümüzde filogeninin bitki taksonomi açısından zorunluluğu hemen hemen tüm sistematikçiler tarafindan kabul edilmektedir. $\mathrm{Bu}$ çalışmada sonuç olarak, bitki moleküler fillogenetiğini konu alan çalışmalarda etkin olarak kullanılan gen, gen bölgesi, gen sayısı, genin hücresel lokasyonun önemli olduğu ortaya konulmuştur. Ayrica, gen veya genlerin dizilerini hizalamada kullanılan birden çok algoritmaların kullanılması elde edilen filogenetik ağacın çok daha güvenilir ve tutarlı sonuçlar vereceği bulunmuştur. Buna bağlı olarak hizalanmış verileri ağaç oluşturmak için kullanan yaygın filogenetik analiz yöntemlerin kullanılmasının önemli olduğu bulunmuştur. Çalışmada hedeflenen amacın daha kapsamlı olması için bundan sonraki çalışmaların, kullanılacak dizilerin kaliteli olduğundan emin olunduktan sonra, takson sayısı daha da genişletilmelidir. Ayrıca, hizalama yazılım programlarının daha da geliştirilmişleri ele alınıp kullanılacak parametre spektrumu oldukça geniş tutulmalıdir.

\section{Teşekkür}

Bu çalışma, Akdeniz Üniversitesi, Bilimsel Araştırma Projeleri Koordinasyon Birimi tarafindan “2011.02.0121.002" No'lu proje ile desteklenmiştir.

\section{Kaynaklar}

Allan, G.J., Francisco-Ortega, J., Santos-Guerra, A., Boerner, E., Zimmer, E.A., 2004. Molecular phylogenetic evidence for the geographic origin and classification of canary island lotus (Fabaceae: Loteae). Molecular Phylogenetics and Evolution, 32(1): 123-138.

Cohen, B.L., Weydmann, A., 2005. Molecular evidence that phoronids are a subtaxon of brachiopods (brachiopoda: phoronata) and that genetic divergence of metazoan phyla began long before the early cambrian. Organisms Diversity \& Evolution, 5(4): 253-273.

Ford, C., Ayres, K., Toomey, N., Haider, N., Stahl, J., Kelly, L., Wikstrom, N., Hollingsworth, P., Duff, R., Hoot, S., Cowan, R., Chase, M., Wilkinson, M., 2009. Selection of candidate coding DNA barcoding regions for use on land plants. Botanical Journal of the Linnean Society, 159(1): 1-11.

Graham, S.W., Olmstead, R.G., 2000. Utility of 17 Chloroplast genes for inferring the phylogeny of the basal angiosperms. American journal of Botany, 87(11): 1712-1730.

Hilu, K.W., Liang, H., 1997. The matK gene: sequence variation and application in plant systematics. American Journal of Botany, 84(6): 830-839.

Hochbach, A., Linder, H.P., Röser, M., 2018. Nuclear genes, matK and the phylogeny of the Poales. Taxon, 67(3): 521-536.

Hollingsworth, P.M., Graham, S.W., Little, D.P., 2011. Choosing and using a plant DNA barcode. PLoS ONE, 6(5): e19254.

İnal, B., Aydın, A., İnce, A.G., Karaca, M., 2017. Genetic relationships among continental cotton species based on ITS1 gene region aligned with different alignment tools. Journal of Molecular Biology and Biotechnology, 1(2): 1-6.

Johnson, L.A.N., Soltis, D.E., 1994. matK DNA sequences andphylogenetic reconstruction in Saxifragaceae s. str. Sysematic Botany, 19(1): 143156.

Kress, W.J., Erickson, D.L., 2007. A two-locus global DNA barcode for land plants: the coding $r b c L$ gene gomplements the non-coding trnH-psbA spacer region. PLoS One, 2(6): e508. 
Lahaye, R., Bank, M.V.D., Bogarin, D., Warner, J., Pupulin, F., Gigot, G., Maurin, O., Duthoit, S., Barraclough, T.G., Savolainen, V., 2007. DNA barcoding the floras of biodiversity hotspots. Pnas, 105(8): 2923-2928.

Lahaye, R., Van Der Bank, M., Bogarin, D., Warner, J., Pupulin, F., Gigot, G., Savolainen, V., 2008. DNA barcoding the floras of biodiversity hotspots. Proceedings of the National Academy of Sciences, 105(8): 2923-2928.

Lei, Y.X., Liu, J., Fan, X., Sha, L.N., Wang, Y., Kang, H.Y., Zhang, H.Q., 2018. Phylogeny and maternal donor of Roegneria and its affinitive genera (Poaceae: Triticeae) based on sequence data for two chloroplast DNA regions (ndhF and trnH-psbA), Journal of Systematics and Evolution, 56(2): 105-119.

Li, X., Yang, Y., Henry, R.J., Rossetto, M., Wang, Y., Chen, S., 2015. Plant DNA barcoding: from gene to genome. Biological Reviews, 90(1): 157-166.

Phong, D.T., Hien, V.T.T., Lieu, T.T., 2018. Nucleotıde diversity of 15 conifer species in vietnam's central highlands based on the analysis of ITS, trnH-psbA, matK, trnL and rpoC1 gene regions. Vietnam Journal of Science and Technology, 56(1): 47-63.

Piredda, R., Simeone, M.C., Attimonelli, M., Bellarosa, R., Schirone, B., 2010. Prospects of barcoding the Italian wild dendroflora: oaks reveal severe limitations to tracking species identity. Molecular Ecology Resources, 11(1): 72-83.

Qui, Y.L., Lee, J.H., Bernasconi-Quadroni, F., Soltis, D.E., Soltis, P.S., Zanis, M., Zimmer, E.A., Chen, Z.D., Savolainen, V., Chase, M.W., 1999. The earliest angiosperms,evidence from mitochondrial, plastid and nuclear genoms. Nature, 402: 404-407.

Ren, B.Q., Xiang, X.G., Chen, Z.D., 2010. Species identification of Alnus (Betulaceae) using nrDNA and cpDNA genetic markers. Molecular Ecology Resources, 10(4): 594-605.

Ro, K.E., Keener, C.S., Mcpheron, B.A., 1997. Molecular phylogenetic study of the Ranunculaceae: Utility of the nuclear 26s ribosomal DNA in inferring intrafamilial relationships. Molecular Phylogenetics and Evolution, 8(2): 117-127.

Ronquist, F., Huelsenbeck, J., 2003. Mrbayes 3: bayesian phylogenetic inference under mixed models. Bioinformatics, 19(12): 1572-1574.

Von Crautlein, M., Korpelainen, H., Pietilainen, M., Rikkinen, J., 2011. DNA barcoding: a tool for improved taxon identification and detection of species diversity. Biodiversity and Conservation, 20(2): 373-389.

Wen, J., Vanek-Krebitz, M., Hoffmann-Sommergruber, K., Scheiner, O., Breiteneder, H., 1997. The potential of betvlhomologues, a nuclear multigene family, as phylogenetic markers in flowering plants. Molecular Phylogenetics and Evolution, 8(3): 317-333.

Yang, Z., Zhao, T., Ma, Q., Liang, L., Wang, G., 2018. Comparative genomics and phylogenetic analysis revealed the chloroplast genome variation and interspecific relationships of corylus (Betulaceae) species. Frontiers in Plant Science, 9: 927.

Yokoyama, J., Suzuki, M., Iwatsuki, K., Hasebe, M., 2000. Molecular phylogeny of Coriaria, with special emphasis on the disjunct distribution. Molecular Phylogenetics and Evolution, 14(1): 11-19. 